DOI 10.37882/2500-3682.2021.04.07

\title{
ОСОБЕННОСТИ ПРЕДСТАВЛЕНИЙ «ОБРАЗА Я» И «ОБРАЗА УСПЕШНОГО МЕДИАТОРА» У СПЕЦИАЛИСТОВ С РАЗНОЙ ПРОФЕССИОНАЛЬНОЙ ОРИЕНТАЦИЕЙ
}

\section{PECULIARITIES OF THE REPRESENTATIONS OF [SELF-IMAGE AND [SUCCESSFUL MEDIATOR IMAGE] FOR THE SPECIALISTS WITH DIFFERENT PROFESSIONAL ORIENTATION}

\section{Vetlinskaya}

Summary: The article describes the results of an empirical study, which is a comparative analysis of mediator image representations among two professional groups. Significant correlations were obtained between assessments of one's personality and that of a "successful» mediator. In contrast to professionals with different professional orientations, the group of mediators tends to identify themselves with the image of a "successful» mediator to a greater extent, which allowed us to identify three trends between the studied indicators, which can be associated with the formation of their professional identity.

Keywords: mediation, mediator's image, mediator's qualities, professional identity, self-determination.

\section{Введение}

И зучение представлений об альтернативных методах урегулирования конфликтов в психологии является важной и необходимой задачей. Считается, что в широком понимании проблема конфликтов относится к группе актуальных социально-психологических проблем, которые остаются мало исследованными. В отечественной и зарубежной литературе можно найти различные позиции на природу конфликтов. Часть специалистов придерживаются теории бесконфликтного, гармоничного развития социальных групп, другие авторы полагают, что конфликт является естественным, необходимым и неизбежным явлением развития общества [8].

В рамках современной действительности можно смело отметить высокую значимость понятия конфликта. Исследования в данной области прошли долгий путь от полного игнорирования данного термина до оценки конфликтов как неотъемлемого явления, требующего детального изучения [8]. Однако, стоит также отметить тенденции в изучении не только самого термина «конфликт», но и перенос интереса на ракурс разрешения
Ветлинская Мария Викторовна аспирант, МГУ имени М.В. Ломоносова m.vetlinskaya@gmail.com

Аннотация: В статье описаны результаты эмпирического исследования, которое представляет собой сравнительный анализ представлений образа медиатора среди двух профессиональных групп. Были получены значимые связи между оценками своей личности и личности «успешного» посредника. В отличие от специалистов с разной профессиональной ориентацией, группа медиаторов склона идентифицировать себя с образом «успешного» посредника в большей степени, что позволило выделить три тенденции между исследуемыми показателями, которые могут быть связаны с формированием их профессиональной идентичности.

Ключевые слова: медиация, образ медиатора, качества посредника, профессиональная идентичность.

проблемных ситуаций. Известно, что в истории большинство разногласий находили свое разрешение путем применения силы, что, безусловно, являлась нормой того или иного времени. В нынешнюю эпоху все больше набирают популярность альтернативные методы урегулирования конфликтов, в частности, к которым относится процедура под названием «медиация». За последние несколько лет можно увидеть преобразование данной процедуры из малоизвестной области в предмет многочисленных обсуждений. В данном исследовании мы опираемся на позицию одного из ведущих экспертов О.В Аллахвердовой, согласно которой медиация определяется как процесс переговоров с участием третьей нейтральной стороны и представляет собой особый социально-психологический процесс, ведущую роль в котором играет посредник - медиатор [2].

Идея обращения к «третьей нейтральной стороне», выступающей в роли посредника в спорах между людьми, существует на протяжении долгого времени. Как указывают многие авторы, история медиация берет свое начало с древнейших цивилизаций, однако, как самостоятельная процедура выделилась лишь во второй половине двадцатого века. Отравной точкой развития 
медиации в России считают принятие Ф3 «Об альтернативной процедуре урегулирования споров с участием посредника (процедуре медиации)» от 27. 07. 2010. [11]. Следует отметить, что юридическая общественность неоднозначно оценивала данную инициативу [7]. Наблюдая за становлением института медиации в России, можно встретить различные точки зрения относительно данного вопроса: часть специалистов придерживаются мнения, согласно которому медиация пока не получила широкого распространения и признания, вторая половина говорит о стремительном развитии обсуждаемого способа разрешения конфликтов в нашей стране. Несмотря на противоречивость представленных позиций, можно также увидеть их взаимосвязь между собой. Иными словами, медиация как относительно новая область общественной жизни столкнулась с многочисленными трудностями, связанными как с законодательной стороной вопроса, так и с социально-психологической, однако, с другой стороны, в настоящее время мы можем наблюдать ее активное преобразование в самостоятельную сферу профессиональной деятельности [6]. Таким образом, исходя из вышеизложенных положений, можно рассматривать медиацию как особую деятельность по разрешению конфликтов, которая регулируется правом. Иными словами, под процедурой медиации мы понимаем способ урегулирования споров при содействии медиатора на основе добровольного согласия сторон в целях достижения взаимовыгодного соглашения. [9] Поэтому в целом о медиации можно сегодня говорить, как о развивающемся социально-правовом институте. Принято считать, что профессиональную медиационную деятельность можно рассматривать не только как социальный институт, но и как профессию, специальность и в результате конкретного применения как должность [6]. Медиация как профессия находится на стадии становления, предпосылки ее появления связаны с развитием в России системы альтернативного разрешения споров и судебной реформой.

Учитывая рассмотренные предпосылки, мы поставили следующую цель исследования: сравнить представления об образе медиатора как специалиста новой отрасли в области разрешения конфликтов у двух профессиональных групп (медиаторов и специалистов из различных практических сфер), а также выявить связи между особенностями представлений своей личности и образа успешного посредника.

\section{Методы исследования}

Выборка исследования. В исследовании приняло участие 77 человек в возрасте от 21 года до 65 лет: 52 специалиста (представители различных специальностей) и 25 медиаторов. В группу специалистов входили представители следующих областей знаний: врачи (6 человек), психологи (6 человек), экономисты (8 человек), юристы (16 человек), менеджеры (7 человек), филологи (3 человека) и представители технической сферы (6 человек). В группу медиаторов (экспертов), согласно первому образованию, входили представители следующих профессиональных сфер: психологии, философии, юриспруденции, экономики.

Схема исследования. В начале респондентам была предоставлена специализированная анкета, затем список качеств, умений и навыков, характерных для личности, способной быть посредником между двумя сторонами (список предоставлялся в двух вариантах: оценить себя и оценить «успешного медиатора») с точки зрения выраженности представленных характеристик. Данный список критериев был составлен на основе теоретического анализа отечественной и зарубежной литературы и выступал в качестве одного из методов исследования - состоял из 24 личностных и профессиональных особенностей медиатора. Для оценки критериев была использована шкала Лайкерта (5 градаций): «совсем не согласен», «слабо выражено», «средняя выраженность», «сильно выражено», «очень сильно выражено».

Качества, умения и навыки мы разделили на шесть содержательных групп:

- Навыки 21 века: нестандартное мышление, критическое мышление;

- Коммуникативные качества: умение слушать, умение понимать эмоции, умение управлять эмоциями, умение аргументировать, коммуникабельность;

- Интеллектуальные качества: умение прогнозировать ситуацию, умение обозначить проблему в сложных ситуациях, умение работать с информацией, эрудированность;

- Качества адаптации к ситуации: способность принять другие точки зрения, умение посмотреть на ситуацию со стороны (особенности восприятия), способность расположить к себе человека (вызвать доверие), психологическая устойчивость, самоконтроль;

- Когнитивные качества: хорошая память, внимательность, наблюдательность, интуиция;

- «Отношение к другим»: доброжелательность, беспристрастность, нацеленность на улучшении ситуации для всех, репутация.

\section{Результаты исследования}

Данное эмпирическое исследование представляет собой сравнительный анализ представлений образа медиатора среди двух профессиональных групп, которые занимаются практической деятельностью в сфере медиации и тех, кто занимается другой профессиональ- 
ной деятельностью. Важным вопросом в изучении представлений является образ медиатора, как специалиста в области переговоров и урегулирования конфликтных ситуаций, который может восприниматься по-разному, не только с точки зрения профессиональных особенностей, но и с позиции личностных качеств.

Обращаясь к данным содержательного анализа анкеты, мы выявили, что большая часть респондентов немного знакома с процедурой медиации. В рамках данной работы медиаторы относятся к группе экспертов, которые хорошо осведомлены в процедуре, в свою очередь, группу специалистов по данным критериям можно рассматривать как контрольную. Представители юридического профиля являются более осведомленными в процедуре медиации среди группы специалистов, что может быть связаны с их профессиональным опытом. Отметим, что большинство специалистов узнали о процедуре медиации от друзей и знакомых. Примечательно, что они не хотели бы получить дополнительное образование в области медиации. В группе медиаторов не было выявлено людей, которые планировали бы уйти из данной сферы, что говорит об их профессиональной заинтересованности. Большинство специалистов разных профилей склонны считать, что медиаторами должны быть люди, имеющие как юридическое, так и психологическое образование. В свою очередь, среди группы экспертов-медиаторов большая часть респондентов считают, что для деятельности медиатора не имеет значение базовое образование, однако они также полагают, что для наиболее эффективной работы медиатор должен обладать знаниями как в психологии, так в юриспруденции. Однако, вне зависимости от принадлежности к той или иной группе, респонденты склонны полагать, что деятельность медиатора - это прежде всего призвание.

В рамках данного исследования нами также был проведен сравнительный анализ выбора личностных и профессиональных качеств посредника среди двух профессиональных групп - проверяется основная гипотеза, согласно которой существуют различия в представлениях об образе медиатора среди групп респондентов.

Рассмотрим результаты количественной выраженности отдельных качеств, согласно данным второго списка критериев, направленного на изучение особенностей личности «успешного» медиатора. Было выявлено, что среди группы специалистов из разных областей знаний выделяются следующие наиболее значимые качества: умение слушать, способность расположить к себе, умение понимать эмоции, умение управлять эмоциями, психологическая устойчивость, умение посмотреть на ситуацию со стороны, умение аргументировать. Ниже всего оцениваются следующие утверждения: нестандартное мышление, доброжелательность, эрудированность, интуиция. Можно заметить примечательный факт, согласно которому медиаторы, в отличие от специалистов разного профиля, присваивают качествам наиболее высокие значения. В их группе самые высокие оценки были получены по качествам «умение слушать» и «умение понимать эмоции». Также в категорию наиболее значимых качеств, умений и навыков можно выделить следующие утверждения: самоконтроль, умение работать с информацией, умение управлять эмоциями, способность расположить к себе, беспристрастность, коммуникабельность. Низкие значение были выявлены по следующим показателям: критическое мышление, эрудированность, интуиция, умение аргументировать. Анализируя полученные данные, можно предположить, что медиаторы выбирают качества в соответствии со своими знаниями и опытом в данной сфере деятельности, так как те качества, которые были выбраны в этой группе сильно отличаются от других респондентов. Однако мы также можем заметить, что в двух профессиональных группах такие качества как «интуиция» и «эрудированность» оцениваются одинаково низко.

Для подтверждения полученных результатов нами был проведен сравнительный анализ между двумя профессиональными группами - для проверки использовался статистический критерий U Манна-Уитни. Так, между группой медиаторов и специалистов были выявлены значимые различия лишь по следующим критериям: умение прогнозировать ситуацию $(p=0,03)$, умение понимать эмоции $(p=0,027)$, критическое мышление $(p=0,042)$, умение аргументировать $(p=0,001)$, самоконтроль ( $p=0,019)$. Исходя из полученных результатов мы можем увидеть, что в группе медиаторов способность в самоконтроле и умение понимать эмоции являются приоритетными в отличие о группы специалистов, которые выделяют другие значимые утверждения, к числу которых относятся в первую очередь умение прогнозировать ситуацию и умение аргументировать.

Нами также были проанализированы результаты по первому списку качеств, умений и навыков, целью которого являлась оценка собственных психологических характеристик. Известно, что изучение профессионального становления человека, включающее в себя особенности представлений об «образе Я» является необходимым в деятельности специалистов, работа которых связана с обеспечением благополучия людей [1]. Таким образом, согласно средним значениям, специалисты оценивают себя как людей, для которых наиболее характерны утверждения: коммуникабельность, умение аргументировать, умение посмотреть на ситуацию со стороны, эрудированность. В свою очередь, как видно из рис.1, медиаторы выделяют в себе следующие наиболее выраженные критерии: умение слушать, нацеленность на улучшении ситуации для всех, способность располо- 


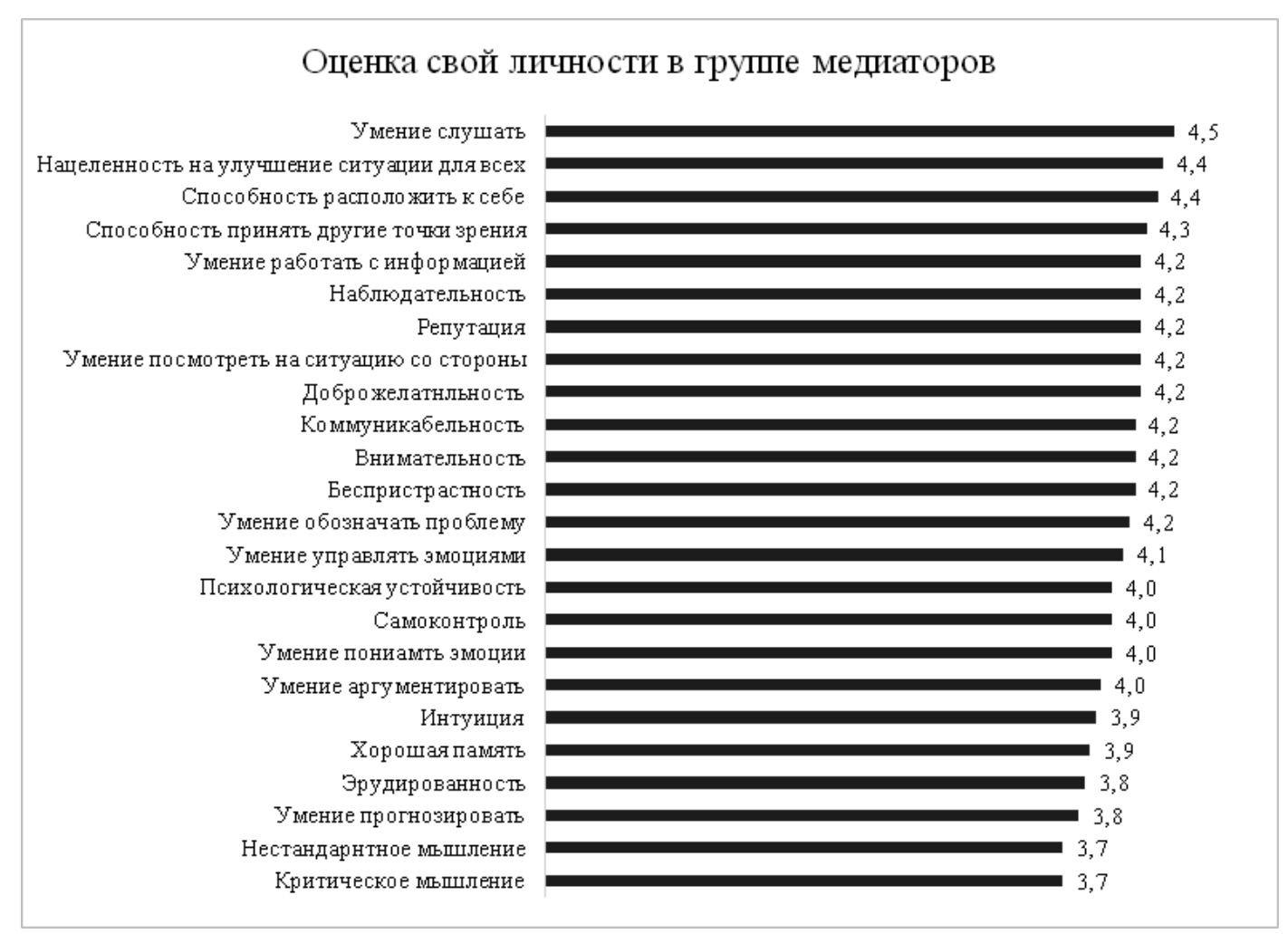

Рис. 1. Профиль оценки своей личности в группе медиаторов

жить к себе, способность принять другие точки зрения. Иными словами, в группе медиаторов мы можем увидеть яркую ориентированность на отношения с другими людьми и желание создать благоприятную атмосферу для взаимодействия.

Как отмечалось ранее, в ходе исследования мы также преследовали цель, согласно которой предполагалось найти связи между оценками своей личности и «личности успешного медиатора». Для выявления взаимосвязи между двумя вариантами списков («качества-Я» и «качества-М») использовался коэффициент ранговой корреляции Спирмена. По результатам корреляционного анализа в группе специалистов из разных областей знаний была выявлена лишь одна значимая связь между качествами «Я-самоконтроль» и «М-эрудированность $(r=0,517, p=0,001)$. Это может говорить о том, что специалисты, приписывающие своей личности качество самоконтроля, считают, что медиатор должен обладать высокими значениями по показателю эрудированности. Как видно из табл.1, в группе медиаторов, были выявлены значимые различия по большим заданным параметрам.

Интерпретируя полученные связи, можно выделить три тенденции по данным показателям, согласно первой, медиаторы могут полагать, что те качества, которые не выражены у них и не выражены с точки зрения их оценок образа успешного медиатора, не будут важны с точки зрения показателя успешности деятельности ме- диатора. В связи с полученными данными, можно предположить, что медиаторы не считают важными для образа успешного медиатора в первую очередь качества, связанные с критическим мышлением. Мы видим связь между умением посмотреть на ситуацию со стороны и способностью к критическому мышлению, однако, полагаем, что развивая в себе это умение медиаторы не будут приближаться к успешной деятельности в работе посредника, в связи с низкой выраженностью данного качества в образе успешного медиатора.

Согласно второй тенденции, медиаторы могут полагать, что те качества, которые слабее выражены у них, но выражены с точки зрения их оценок образа успешного медиатора, могут быть связаны с успешностью их работы в будущем. Иными словами, развивая в себя способность, связанную с психологической устойчивостью, медиаторы могут проявлять доброжелательность в своей работе в большей степени. Аналогичный вывод можно предположить относительно полученных корреляций, связанных с умением аргументировать. Развивая в себе этот навык, медиаторы будут приближаться к более доброжелательному общению и умению нестандартно решить конфликтную ситуацию. На последнее также может оказывать влияние способность в умении посмотреть на ситуацию со стороны. Таким образом, развив в себе эти навыки и умения, они смогут приблизиться к своему личному представлению об образе успешного медиатоpa. 
Показатели корреляционного анализа по группе медиаторов

\begin{tabular}{|c|c|c|c|}
\hline Качества-я & Качества-М & $\begin{array}{c}\text { Показатель коэффициента ранговой } \\
\text { корреляции Спирмена }\end{array}$ & 3начимость \\
\hline Умение прогнозировать & Нестандартное мышление & $\mathrm{r}=0,528$ & $\mathrm{p}=0,007$ \\
\hline Умение прогнозировать & Критическое мышление & $\mathrm{r}=0,574$ & $\mathrm{p}=0,003$ \\
\hline Критическое мышление & Критическое мышление & $\mathrm{r}=0,585$ & $\mathrm{p}=0,002$ \\
\hline Психологическая устойчивость & Доброжелательность & $\mathrm{r}=0,588$ & $\mathrm{p}=0,002$ \\
\hline Репутация & Доброжелательность & $\mathrm{r}=0,539$ & $\mathrm{p}=0,005$ \\
\hline Репутация & Репутация & $\mathrm{r}=0,707$ & $\mathrm{p}=0,001$ \\
\hline Умение аргументировать & Доброжелательность & $\mathrm{r}=0,557$ & $\mathrm{p}=0,004$ \\
\hline Умение аргументировать & Нестандартное мышление & $\mathrm{r}=0,519$ & $\mathrm{p}=0,008$ \\
\hline Умение посмотреть на ситуацию со & Коммуникабельность & $\mathrm{r}=0,526$ & $\mathrm{p}=0,007$ \\
\hline стороны & Доброжелательность & $\mathrm{r}=0,527$ & $\mathrm{p}=0,007$ \\
\hline
\end{tabular}

Согласно третьей тенденции, медиаторы, приписывающие своей личности высокие значения по качествам своего образа и высокие значения по образу успешного медиатора, склонны идентифицировать себя с ним. Мы можем предполагать, что высокие значения, полученные по оценкам, связанным с умением посмотреть на ситуацию со стороны в своем образе, будут отражаться в работе медиатора, когда речь идет о доброжелательности и коммуникативных способностях. Иными словами, умение посмотреть на ситуацию со стороны будет связана с успешной работой медиатора в сфере межличностного взаимодействия. Похожий вывод можно сделать о качестве, связанным с репутацией посредника, который определяет его профессиональный образ и статус. Если медиатор будет положительно оценивать свою роль, тем более доброжелательным он будет в глазах других и обладать более высокой репутацией. Вероятно, что подобные результаты свидетельствуют о том, что выраженность данных качеств может быть связана с важными умениями и навыками в образе успешного медиатора, которые присутствуют в структуре их профессиональной идентичности.

\section{Зак^ючение}

Медиация как способ урегулирования конфликтов в различных формах существует на протяжении долгого времени, однако она никогда не имела правовую базу, и все конфликты разрешались по правилам того или иного времени. С развитием общества медиация приобрела законодательную основу, которая способствовала ее внедрению в разные страны. Можно с уверенностью сказать, что процедура получила широкое распространение и популярность на Западе, в России медиация находится на стадии становления. Особое внимание в развитии процедуры уделяется вопросу подготовки квалифицированных специалистов в данной области: существует множество вопросов, связанных с базовым образованием посредника, его профессиональной ориентацией, личностными особенностями. В рамках данного исследования мы попробовали изучить формирующийся образ медиатора среди практикующих медиативную деятельность специалистов и тех, кто занимается другой профессиональной деятельностью, а также затронули тему профессиональной идентичности респондентов. Иными словами, нами были получены результаты, согласно которым мы смогли получить данные в пользу основных гипотез исследования. Особенно важным представляются результаты, согласно которым специалисты из разных областей знаний не идентифицирует себя с образом «успешного медиатора» и строят свой образ профессионала, чего нельзя сказать о группе практикующих специалистов-медиаторов. Вероятно, полученные тенденции при исследовании корреляционных связей, могут быть связаны с формированием профессиональной идентичности посредников как людей, которые развиваются в рамках новой «помогающей» профессии.

Подводя итоги исследования, можно еще раз отметить, что в России институт медиации только зарождается, к сожалению, многие специалисты даже не осведомлены о существовании данной процедуры и принципах ее работы. Как уже было сказано ранее, работа посредников является сердцевиной данной деятельности, поэтому представляется актуальным развивать исследования по данной теме и внедрять их в общественное сознание людей с целью популяризации новой значимой для общества профессии. 


\section{ЛИТЕРАТУРА}

1. Абдуллаева М.М. Особенности «образа Я» профессиональных юристов // Прикладная юридическая психология. - 2008. - №2 - С.108-121.

2. Аллахвердова 0.В., Медиация. Пособие для посредников, - СПб: СПб, 1999.

3. Ветлинская М.В. Анализ отечественных и зарубежных представлений о роли личностных и профессиональных качеств успешного посредника // Сборник материалов Международной научно-практической конференции (2-3 ноября 2020 г.) под редакцией Н.И. Гайдаенко Шер. - Иваново - С.16-24.

4. Бегичев М.М., Власов А.В. Проблемы противодействия экономическим преступлениям в современных условиях. Путеводитель предпринимателя. 2020. T. 13. № 1. C. 108-117.

5. Иванова Е.Н. Методы эффективной работы медиатора в разных сферах практики // Вестник Нижегородского университета им. Н.И. Лобачевского. 2015. - №4. - С. 131-136.

6. Карпенко А.Д., Осиновский А.Д. Медиация: учебник. - М.: Статус, 2016.

7. Лазарев С.В. Основы судебного примирения. - М: Инфотропик Медиа, 2011.

8. Леонов Н.И. Конфликтология: учебное пособие - М.: Издательство Московского психолого-социального института; Воронеж: Издательство НПО «МОДЭК», 2006.

9. Мельниченко Р.Г. Медиация: учебное пособие для бакалавров. - М.: Издательско-торговая корпорация «Дашков и К», 2014.

10. Пряжников Н.С. Активизирующая профконсультация: теория, методы, программы. Методические пособие. - М.: Издат. Центр «Академия», 2014.

11. Федеральный закон от 27.07.2010 N 193-Ф3 «06 альтернативной процедуре урегулирования споров с участием посредника (процедуре медиации)» // СПС КонсультантПлюс

(с) Ветлинская Мария Викторовна (m.vetlinskaya@gmail.com).

Журнал «Современная наука: актуальные проблемы теории и практики»

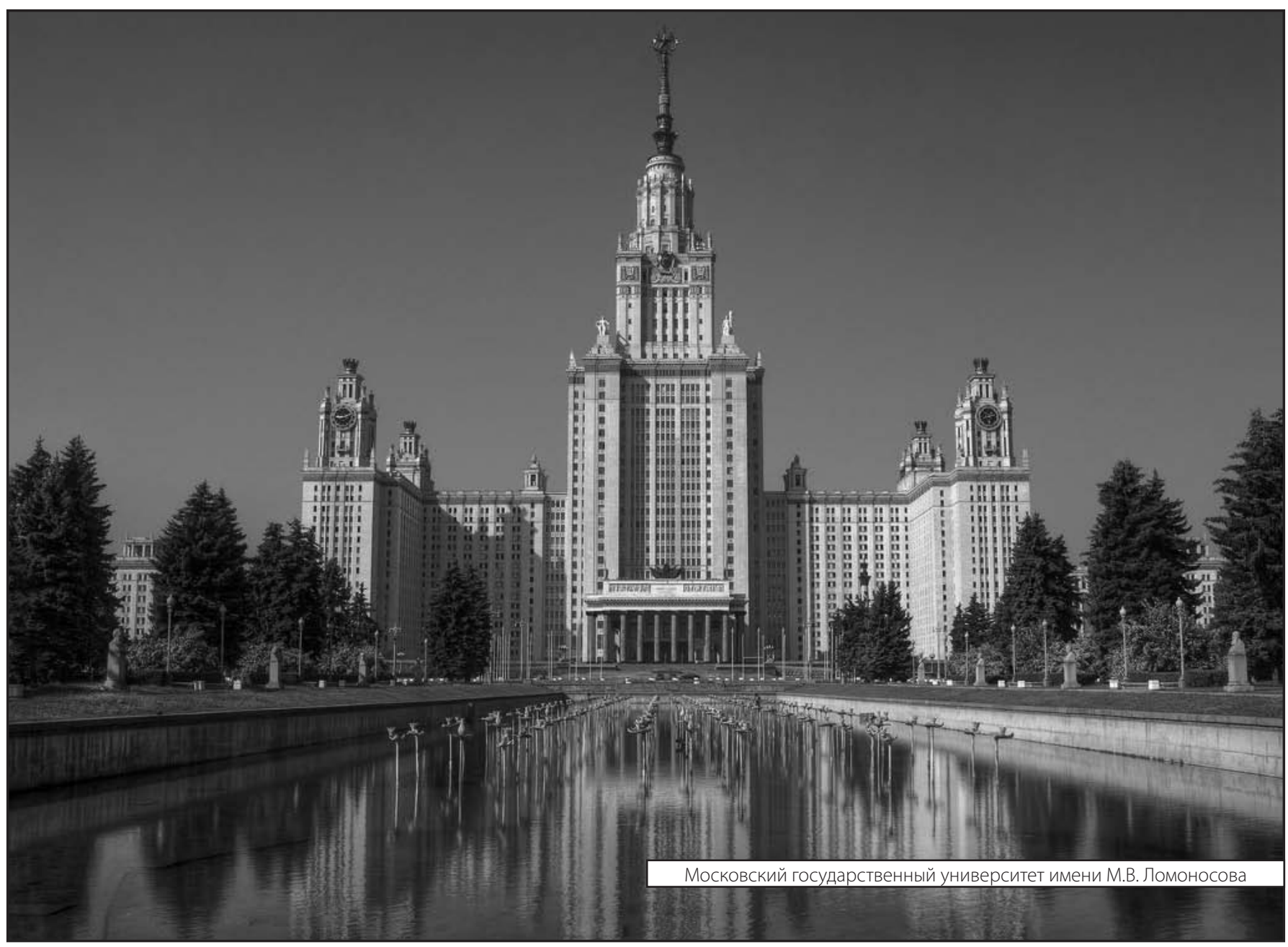

